\title{
New understanding of pectin as a bioactive dietary fiber: a review
}

\author{
Tomio Yabe ${ }^{\mathrm{a}, \mathrm{b}^{*}}$
}

\begin{abstract}
aDepartment of Applied Life Science, Faculty of Applied Biological Sciences, Gifu University, 1-1 Yanagido, Gifu, Gifu 501-1193, Japan ${ }^{b}$ Center for Highly Advanced Integration of Nano and Life Sciences, Gifu University (G-CHAIN), 1-1 Yanagido, Gifu, Gifu 501-1193, Japan *Corresponding author: Tomio Yabe, Department of Applied Life Science, Faculty of Applied Biological Sciences, Gifu University, 1-1 Yanagido, Gifu, Gifu 501-1193, Japan. Tel: +81-58-293-2913; E-mail: yabet@gifu-u.ac.jp
\end{abstract}

DOI: $10.31665 / \mathrm{JFB} .2018 .3152$

Received: May 28, 2018; Revised received \& accepted: August 28, 2018

Citation: Yabe, T. (2018). New understanding of pectin as a bioactive dietary fiber: a review. J. Food Bioact. 3: 95-100.

\begin{abstract}
Dietary fibers perform various physiological and metabolic functions in the human body. Pectin, a water-soluble dietary fiber, is a natural complex heteropolysaccharide composed of galacturonic acid residues and a variety of neutral sugars such as rhamnose, galactose, and arabinose. It is a constituent of the cell wall and is conserved in all terrestrial plants. Besides the health benefits associated with dietary fibers, new health-related functions are being explored, particularly those related to their bioactive roles, inducing morphological changes in the small intestine. This review discusses the structure of pectin, its widely known physiological functions, and the new developments in pectin research.
\end{abstract}

Keywords: Pectin; Heparan Sulfate; Intestine; Fibronectin; Integrin.

\section{Introduction}

Dietary fibers perform various physiological and metabolic functions in humans, including reduction in the risk of developing various diseases such as hypertension, diabetes, obesity, and gastrointestinal disorders (Anderson et al., 2009). The high consumption of dietary fibers has been shown to improve serum lipid concentration, lower blood pressure, improve blood glucose control in diabetes, contribute to weight loss, and enhance immune function (Anderson et al., 2009). These physiological effects are presumably associated with the fermentation of dietary fibers by the colonic microflora that results in the production of short-chain fatty acids (Brown et al., 1999). On the other hand, dietary fibers exert direct (microflora-independent) effects on the gastrointestinal tract. Several studies have shown that pectin, a soluble dietary fiber, induces morphological changes and promotes crypt formation in the small intestine (Langhout et al., 1999; McCullough et al., 1998; Tasman-Jones et al., 1982). However, the mechanisms underlying the pectin-induced morphological alterations in the small intestine remain questionable.

The intestinal epithelium of the small intestine is continuously renewed by the generation of cells and migration of stem cells located at the bottom of the crypts to the top of the villi (Babyatsky and Podolsky, 1999). Wnt proteins play a key role in the development and homeostasis of the intestinal epithelium (Crosnier et al., 2006), while heparan sulfate (HS) plays a critical role in the intestinal crypt homeostasis by regulating the Wnt affinity (Yamamoto et al., 2013).

This review discusses the structure of pectin, its widely known physiological functions. The new developments in pectin research are also reported .

\section{Historical background}

Pectin is universally present in each organ of terrestrial plants in the meristematic tissue and parenchyma (Maxwell et al., 2012; Srivastava and Malviya, 2011). At the cellular level, pectin is ubiquitous in the cell wall and the middle lobe of the plant cell, but its quantity and quality vary greatly between plant species and sites (Naqash et al., 2017).

The word pectin is derived from the Greek word "pektos," which means "rich, solidify," coined by a French chemist Braconnot, who also isolated chitin and glycine (Braconnot, 1825). However, the substance that corresponded to pectin was a jellylike molecule discovered for the first time in 1790 from tamarind 
by a French chemist Vauquelin (Vauguelin, 1790). For more than 200 years, the research on pectin has been continued worldwide.

In this period, various compounds related to pectin have emerged, causing confusion among the researchers. Although the definition and unified name of pectin and related substances were released by the American Chemical Society (Kertesz et al., 1944), the confusion persists. In Japan, pectic substances, protopectin, pectinic acid, and pectic acid, are commonly used not only in the research field but also in the industry. Pectic substances refer to pectin or a group of polysaccharides extracted from the cell walls using hot water, aqueous solutions such as ammonium oxalate, weak acids, or chelating agents. Protopectin is an insoluble pectic substance known to be present in immature fruits. Pectinic acid, or narrow pectin, is a soluble substance derived from protopectin by enzymatic action in mature fruits. Pectinic acid has a methyl ester group (methoxy group); however, it gets decomposed to its insoluble state and contains no methyl ester group, a form also called as the non-esterified pectin. Pectic acid is a polymer of galacturonic acid, a constituent sugar, without any methyl ester group.

Pectin has been used in food items such as jams and jellies for its gel-forming ability. Pectin is not used as a raw material but serves as a food additive. As it is a type of dietary fiber present in vegetables and fruits, the applications of pectin in the form of a healthy food ingredient have gained increasing attention in recent years.

\section{Chemical structure of pectin}

Like cellulose and hemicellulose, pectin is one of the major molecules constituting the cell wall of terrestrial plants (Maxwell et al., 2012; Srivastava and Malviya, 2011). Pectin is a polysaccharide universally included in the primary cell wall that lacks lignin during elongation and growth as well as in the middle lobe, a thin layer that facilitates attachment between adjacent cells. The other secondary cell wall constituting the plant cell wall is a structure formed by the accumulation of lignin inside the primary cell wall and lacks pectin (Albersheim et al., 2011). In the primary cell wall, pectin exists along with xyloglucan as a matrix polysaccharide between cellulose fine fibers. While xyloglucan crosslinks fine fibers, pectin plays a role of filling the gaps. Pectin comprises about $30-35 \%$ of cell walls in genuine dicotyledonous plants and $1-5 \%$ cell walls in monocotyledonous plants, ferns, and bryophytes (Albersheim et al., 2011).

Pectin is a complex polysaccharide of various monosaccharides. In 1917, Ehrlich proposed that pectin is a polymer of D-galacturonic acid (GalA) (Ehrlich, 1917), while Henglein and Schneider in 1936 reported that galacturonic acid was linearized by an $\alpha-1,4$ bond (Henglein and Schneider, 1936). Currently, it is believed that pectin has several structural domains that contain multiple monosaccharides other than galacturonic acid. Three of the main structural regions are homogalacturonan (HG), rhamnogalacturonan-I (RG-I), and rhamnogalacturonan-II (RG-II) that are thought to be linked to each other by covalent bonds, although their respective positional relationship and bonding mode are unknown (Mohnen, 2008).

Homogalacturonan serves as a structural region occupying about $65 \%$ of typical pectin and is a linear polysaccharide carrying D-galacturonic acid residues linked together by the $\alpha-1,4$ bond. During HG biosynthesis in the plant cell, D-galacturonic acid is initially polymerized by galacturonic acid transferase on the Golgi apparatus membrane (Atmodjo et al., 2011) with a simultaneous catalysis of the carboxy group of the galacturonic acid residue by the enzyme methyltransferase in a methyl esterification reaction (Held et al., 2011). It is secreted into the cell wall in a highly es-

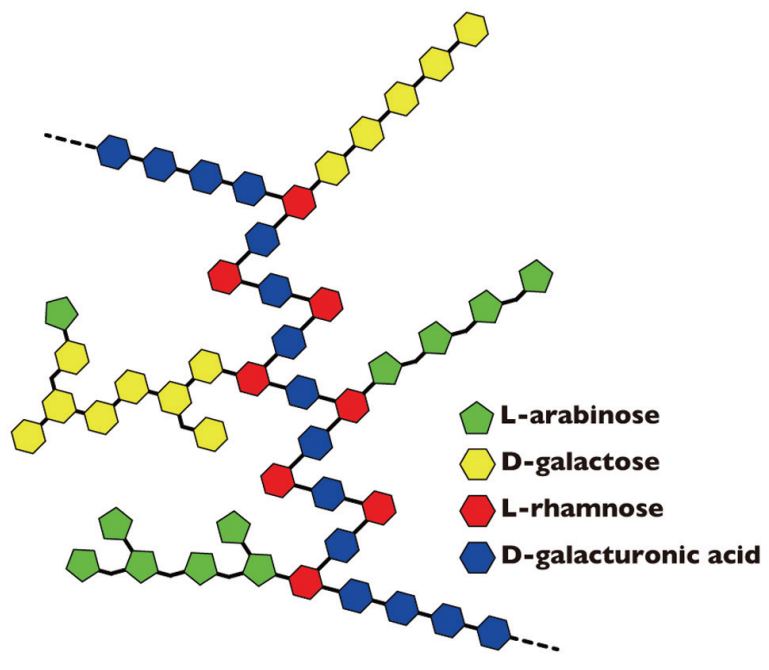

Figure 1. Model of structure for rhamnogalacturonan-I (RG-I).

terified state and then undergoes a partial catalysis by the pectin methyl esterase family enzymes present in the cell wall to form the complete HG. The acetylated hydroxyl groups at positions 2 or 3 have also been thought to be involved in this process (Schols and Voragen, 2003). Although the degree of methyl esterification differs between the plant species and tissues, the carboxy group of the galacturonic acid residue is exposed and bound to the calcium ion when all the methyl ester groups on HG are demethylated in a linear fashion. As a result, it crosslinks intramolecularly and intermolecularly in HG to promote gelling of pectin and hardens the cell wall. On the other hand, demethylation of the methyl ester group on HG makes the molecule susceptible to decomposition by some enzymes such as endopolygalacturonase and eventually softens the cell wall. Thus, HG functions as a key factor in the process of strengthening the primary cell wall.

The RG-I region (Figure 1) is a structural region that accounts for $25-35 \%$ of a typical pectin molecule. RG-I is a complex carbohydrate with repeating units of disaccharides D-galacturonic acid and L-rhamnose (Rha) $[\rightarrow 4)-\alpha$-D-GalA- $(1 \rightarrow 2)-\alpha$-L-Rha- $(1 \rightarrow]$, wherein the side chain is bound to the hydroxy group at the fourth position (rarely third position) in the rhamnose residue. The side chains are arabinans mainly composed of $\alpha-1,5$ linkages of Larabinose and galactans comprising $\beta-1,4$ linkages of D-galactose (Voragen et al., 2009). Furthermore, arabinogalactan in the side chain is known to be involved in various physiological functions.

Rhamnogalacturonan-II is the most complicated structural region occupying about $10 \%$ of a typical pectin molecule. RG-II is very well preserved through the process of evolution and is present in the primary cell wall of all terrestrial plants. The basic structure is a complex polysaccharide region having an average molecular weight of 5,000 Da and carrying four side chains of different structures bonded to a galacturonic acid polymer (degree of polymerization of 9 to 12) of D-galacturonic acid residues linked together by the $\alpha-1,4$ bond (Bar-Peled et al., 2012). RG-II may exists alone or in the form of cross-linked sites forming a diester between boric acid molecules of neighboring RG-II regions (O'Neill et al., 2004).

\section{Food applications of pectin}

Pectin is generally well known as a component of jam. This in- 
cludes commercial jams as well as those easily made at home by adding sugar to fruits such as strawberries.

Pectin is widely used as a food additive (thickening stabilizer) in commercially available jams, fruit jelly, ice cream, and other products. In Japan, it is mandatory to mention the food additives used in the manufacturing of processed foods in the list of content placed on the packaged container; hence, pectin would be included in the contents when used. The food additives used for the prescribed eight types of applications such as preservatives and sweeteners are described in the form of their names together with their applications. For instance, the pectin classified as a thickening stabilizer would be indicated as "thickener (pectin)," "gelling agent (pectin)," or "paste (pectin)".

Among food additives, the thickening stabilizer refers to a polymeric substance that is dissolved or dispersed in water to provide consistency, a known property of pectin. In addition, the thickening stabilizer is further classified according to the usage method. High viscosity in a small amount suggests its application as a "thickener." On the other hand, an additive used as a solidifying liquid in the form of a jelly is termed as "gelling agent." The additive is termed as a "stabilizer" when it is used for the purpose of increasing the viscosity to uniformly stabilize food ingredients, while it is referred to as "glue" when used for all of the above purposes. Pectin is used for all of these applications, indicative of its diverse functions.

Pectin used as a food additive is extracted and separated from citrus peel (mainly lemon), apple squeezed lees, and beet pulp (squeezed lees of sugar beet), among others. The extracted pectin is roughly divided into two types depending on the proportion of the methyl ester group of pectinic acid, namely the high methoxypectin (HM pectin) having a degree of esterification (ratio of methyl esterified galacturonic acid residues) of $50 \%$ or more and forming a hydrogen bond-type gel, and the low methoxypectin (LM pectin) having a degree of esterification of less than $50 \%$ and forming an ionic bond-type gel.

High methoxypectin is used for general jams and jellies. The addition of an acid to a pectin colloid with a negative charge results in the suppression of the dissociation of the carboxy group. As a consequence, the substance becomes electrically neutral, leading to the aggregation of pectin. Furthermore, the role of sugar added to jams is to cause dehydration and help stabilize the gel. As HM pectin containing a large amount of methyl ester group originally exhibits low electric charge, it easily forms gels even at low sugar concentration and high pH (Silva and Rao, 2006). High methoxypectin is used as a stabilizer and thickener for beverages and fermented milk and a gelling agent.

Low methoxypectin exhibits great gelling properties in the presence of bivalent metal ions such as calcium and magnesium in the absence of sugar. This property is associated with two molecules of pectin that are crosslinked by calcium via a carboxy group owing to the less methyl esterified galacturonic acid, resulting in the formation of a network structure that undergoes aggregation (Silva and Rao, 2006). Low methoxypectin is used in coatings, producing gloss on the surface of foods, preventing hardening of ice cream, and as stabilizers for frozen meat juice.

\section{Physiological functions of pectin}

Pectin is a food ingredient classified as dietary fiber, as it fails to undergo degradation by human digestive enzymes and is not absorbed as a nutrient component in the small intestine. The term dietary fiber was coined by Hipsley (Hipsley, 1953). In 1972, Trow- ell defined dietary fiber as "a structural residue of a plant cell not affected by human digestive enzymes" (Trowell, 1972) in response to "fiber hypothesis for colorectal cancer" announced by Burkitt the previous year (Burkitt, 1971). Since then, research on dietary fiber has advanced worldwide, and various health maintenance and regulatory functions have been reported. In particular, studies on dietary fiber are important in the Japanese society and have contributed to health promotion and disease prevention. For instance, the food containing dietary fiber is cited as "food to adjust stomach condition" under the "Food for Specified Health Uses (FOSHU)" according to Article 26 of the Health Promotion Law in Japan.

Among dietary fibers, pectin is shown as a component that affects physiological functions. In particular, pectin regulates the internal environment of the gastrointestinal lumen $(\mathrm{pH}$, quantity and quality of intestinal bacteria, etc.) and generates short-chain fatty acids following the action of the intestinal bacteria. Furthermore, pectin regulates gastrointestinal functions through physical and chemical interactions with the gastrointestinal tract. Since $90-100 \%$ of pectin as a dietary fiber is decomposed by the intestinal bacteria, the actions by pectin mainly takes place in the small intestine where little intestinal bacteria exist, and the structure of pectin is closely related to its characteristics.

There is no evidence to clearly show the regulation of the gastrointestinal function through chemical interactions between pectin and the gastrointestinal tract, but there are several reports that support this hypothesis. For instance, it has been reported that the small intestinal mucosal structure of people in developing countries was significantly different from that of people in developed countries (Baker, 1973). This difference was associated with the variation in diet or the amount of dietary fiber ingested. Animal experiments have suggested that the influence on the small intestinal mucosa structure is derived from pectin. It was reported that the crypts in the jejunum and ileum of rats fed with diets containing $18 \%$ pectin got deeper than those from rats without pectin supplementation (Brown, et al., 1979). The mucosal proliferation of rat small intestine was promoted by pectin (Chun et al., 1989; McCullough et al., 1998), and the villi of rats and chickens ingesting feed containing high pectin became irregular (Cassidy et al., 1982; Langhout et al., 1999; Tasman-Jones et al., 1982).

The physiological functions of pectin reported so far include plasma cholesterol normalization activity (Terpstra et al., 1998), suppression of cancer liver metastasis (Tazawa et al., 1999), suppression of food allergy (Lee et al., 2004), and antitumor activity (Ohkami et al., 1995; Olano-Martin et al., 2002). Other new physiological functions are expected to appear in the future.

\section{Induction of morphological changes in the small intestinal villi by pectin}

The molecular mechanism underlying the change in the morphology of the small intestinal villi induced by pectin is yet unclear. To undergo changes in the morphology of the intestinal tract, it is necessary that the small intestinal epithelial cells recognize the molecular structure of pectin upon oral ingestion of pectin (Figure 2 ). It is possible that the proteins on the epithelial cell membrane interact with pectin in a structure-specific manner and transmit any information from the inside of the cell. A protein that recognizes pectin has been identified (Nishida et al., 2014; 2015). These authors tried to elucidate the underlying molecular mechanism by observing and analyzing cell response upon pectin administration in differentiated Caco- 2 cells, model cells of the small intestinal epithelium. 


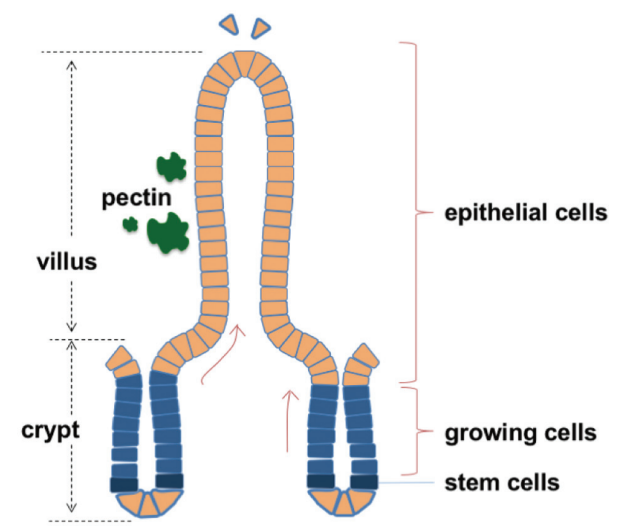

Figure 2. Schematic diagram of small intestinal villi.

In the analysis of the cellular response, Nishida et al. (2014; 2015 ) focused on HS of the sugar chain that is ubiquitously present on the cell surface and in the extracellular matrix of all animal cells. HS belongs to the glycosaminoglycan type of sugar chain and is a linear polysaccharide of repeated disaccharide units of $\mathrm{N}$ acetylglucosamine and glucuronic acid or iduronic acid residues in the Golgi apparatus. Once the backbone is synthesized, HS is sulfated at the $\mathrm{N}, 6-\mathrm{O}$, and 3-O positions of glucosamine and 2-O position of uronic acid residues by multiple enzymes to produce sugar chains with diverse sulfation patterns (Habuchi, 2000; Iozzo and Schaefer, 2015; Li and Kusche-Gullberg, 2016; Sarrazin et al., 2011). HS is transported to the cell surface, wherein HS 6-Oendosulfatases (Sulf1 and Sulf2) modify the sulfated structure of HS (Frese et al., 2009; Lamanna et al., 2008). Based on the sulfated structure synthesized by the enzymes, HS plays essential roles in various physiological activities as a receptor or co-receptor for different ligands such as Wnt, Hedgehog, fibroblast growth factors, and transforming growth factor- $\beta$ and modulates the biological activities of these proteins (Bernfield et al., 1999; Bishop et al., 2007). The recognition of pectin by differentiated Caco-2 cells would result in the change in the structure of HS on the cell surface. Therefore, studies have examined whether the expression of sulfotransferase and desulfating enzyme, which determine the sulfated structure of differentiated Caco-2 cell surface HS, was affected by the addition of pectin (Nishida et al., 2014; Nishida et al., 2015).

Disaccharide compositional analysis revealed that the sulfated structures of HS were markedly changed by pectin administration (Nishida et al., 2014). Real-time reverse transcription polymerase chain reaction (RT-PCR) showed that pectin upregulated human HS 6-O-endosulfatase-2 (HSulf-2) expression and markedly inhibited HSulf-1 expression. Furthermore, inhibition analysis suggested that the pretreatment with fibronectin IIIIC fragment, arginylglycylaspartic acid (RGD) peptide, and extracellular-signal-regulated kinase (ERK)-1/2 inhibitor suppressed the pectin-induced HSulf-2 expression (Nishida et al., 2014). These observations indicate that pectin induced the expression of HSulf-2 through its interaction with fibronectin, $\alpha 5 \beta 1$ integrin, and ERK1/2, thereby regulating the sulfated structure of HS on differentiated Caco- 2 cells.

The biological significance of the effect of pectin on HS in differentiated Caco-2 cells was investigated (Nishida et al., 2015). An in vitro intestinal epithelium model was constructed by co-culturing differentiated Caco- 2 cells and rat IEC- 6 cells, which were used as models of intestinal epithelium and intestinal crypt cells, respectively. Pectin-treated differentiated Caco-2 cells promoted the growth of IEC- 6 cells. Real-time RT-PCR analysis and western

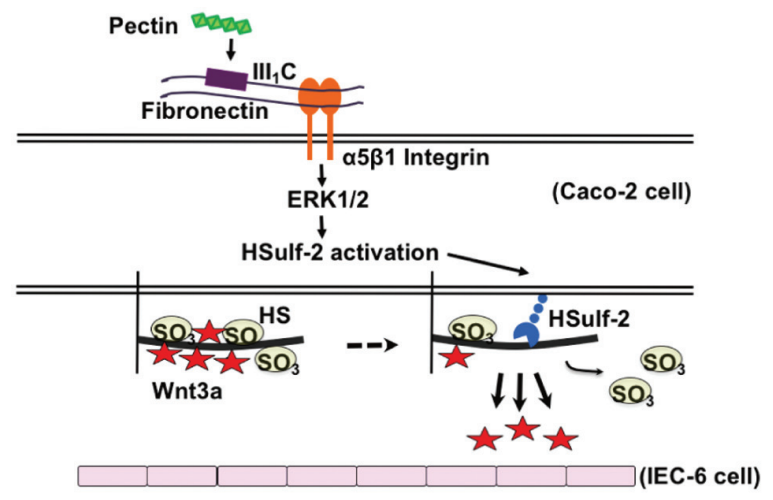

Figure 3. Summary of growth promotion of crypt proliferating cells via small intestinal villous epithelial cells by pectin.

blotting showed that the relative mRNA and protein expression levels of Wnt3a were upregulated by pectin treatment in differentiated Caco-2 cells (Nishida et al., 2015). Surface plasmon resonance spectroscopy analysis demonstrated that the pectin-induced structural alteration in HS markedly decreased its interaction with Wnt3a (Nishida et al., 2015). These observations indicate that pectin altered the sulfated structure of the cell surface HS to promote the secretion of Wnt3a from differentiated Caco-2 cells and that Wnt3a stimulated the proliferation of IEC-6 cells (Figure 3 ).

Lamanna et al. (2008) reported that the knockout of Sulfs affected the mRNA expression of 6-O-sulfotransferases (6-OSTs) and 2-OST-1. As pectin administration resulted in the marked inhibition of HSulf-1 expression, the effects of pectin on 6-OSTs and 2-OST-1 mRNA expressions were investigated in differentiated Caco-2 cells (Nishida et al., 2014). HS-modifying enzymes have multiple isoforms and their expression patterns exhibit tissue- and developmental stage-specific variations (Nogami et al., 2004). After pectin stimulation, 6-OST-1 mRNA expression increased by about three-fold and then gradually decreased to the normal level. On the other hand, no obvious increases were observed in 6-OST-2 mRNA expression. The increase in 6-OST-1 expression probably resulted in an increase in the ratio of $\Delta$ Di-di6S. 6-OST-3 expression was undetected in differentiated Caco-2 cells. The relative 2-OST-1 mRNA expression decreased and the ratio of $\triangle \mathrm{Di}-\mathrm{NS}$ was unaffected by pectin treatment, suggesting that the decreased ratio of $\Delta \mathrm{Di}$-diS2 was caused by the downregulated expression of 2-OST-1 (Nishida et al., 2014).

Nagel et al. (2008) suggested that the enzymatically modified apple pectin interacted with Swiss 3T3 fibroblast cells and their interactions were mediated by $\alpha 5 \beta 1$ integrin. As Swiss $3 \mathrm{~T} 3$ fibroblast cells express fibronectins in the extracellular matrix (Verderio et al., 1998), the effect of pectin on the upregulated HSulf-2 mRNA expression was mediated by fibronectin and $\alpha 5 \beta 1$ integrin (Nishida et al., 2014). The galacturonan fragment of pectin from the aerial part of Comarum palustre L. was assumed to interact with the $\beta 1 / \beta 2$ chain of integrins (Popov et al., 2005), suggesting that $\beta 1 / \beta 2$ integrins on the Caco- 2 cells may support the binding between pectin and fibronectin.

Integrins mediate cell adhesion to the extracellular matrix proteins and regulate a number of intracellular signal transduction pathways. Integrins activate ERK1/2 by at least two different signaling pathways. Activated $\alpha 5 \beta 1$ integrin activates ERK1/2 via Src with tyrosine-phosphorylated focal adhesion kinase, leading to the subsequent activation of the mitogen-activated protein kinase (MAPK) pathway (Gilcrease, 2007; Schlaepfer et al., 1998; Schlaepfer and Hunter, 1997). On the other hand, the association 
of $\alpha 5 \beta 1$ integrin with the membrane protein caveolin results in the activation of ERK $1 / 2$, followed by the subsequent phosphorylation of the tyrosine of the adaptor protein Shc by the enzyme tyrosine kinase Fyn (Gilcrease, 2007; Wary et al., 1996; Wary et al., 1998). In Caco-2 cells, $\alpha 5 \beta 1$ integrin mediates fibronectin-induced epidermal growth factor receptor (EGFR) activation, which leads to EGFR-mediated activation of ERK1/2 and cell proliferation (Kuwada and Li, 2000; Kuwada et al., 2005). As Ai et al. suggested that QSulf-1 removes 6-O-sulfates from HS chains on the surface of HS proteoglycans to regulate the binding of Wnt proteins (Ai et al., 2003), pectin-induced HSulf-2 expression may affect the affinity for Wnt proteins.

As the cell surface HS is mainly expressed on the basolateral side of polarized Caco-2 cells (Mertens et al., 1996) and predominantly located on the basement surface in the developing intestine (Simon-Assmann, 1989), pectin may promote the secretion of Wnt3a from differentiated Caco- 2 cells by changing the sulfated structure of HS to reduce its interaction with Wnt3a. Furthermore, the secretion of Wnt proteins is usually inefficient and attempts to characterize Wnt proteins are restricted by their high degree of insolubility (Willert et al., 2003). As it is important for the cell to express HS on its surface to facilitate the functioning of Wnt proteins, further studies are required to investigate this point. Moreover, Wnt3a is mainly expressed in Paneth cells that reside next to the intestinal stem cells (Sato et al., 2011). As transit-amplifying cells in crypts migrate along the crypt-villus axis, pectin may promote morphological changes in the small intestine by regulating the affinity between Wnt3a and HS in crypts. This study provided fundamental insights into the mechanisms of pectin-induced morphological changes in the small intestine in vivo.

\section{Conclusion}

As a food ingredient, pectin plays important physiological functions during its movement through the intestinal tract. Pectin is used for fermentation by intestinal bacteria after reaching the large intestine and serves as a key secondary metabolite. However, some other physiological functions of pectin are yet undetermined. The hypothesis that proteins recognizing pectin are expressed on the intestinal epithelial cells may be the first step toward finding new functions of pectin. The possibility that the epithelial cells of the intestinal tract exhibit the function of distinguishing dietary fibers may open new avenues for exploring the physiological functions of dietary fibers.

\section{References}

Ai, X., Do, A.T., Lozynska, O., Kusche-Gullberg, M., Lindahl, U., and Emerson, C.P. (2003). QSulf1 remodels the 6-O sulfation states of cell surface heparan sulfate proteoglycans to promote Wnt signaling. J. Cell Biol. 162: 341-351.

Albersheim, P.Darvill, A.Roberts, K.Sederoff, R., and Staehelin, A. (Ed.). (2011). Plant Cell Walls. Garland Science, New York, NY.

Anderson, J.W., Baird, P., Davis, R.H., Ferreri, S., Knudtson, M., Koraym, A. Waters, V., and Williams, C.L. (2009). Health benefits of dietary fiber. Nutr. Rev. 67: 188-205.

Atmodjo, M.A., Sakuragi, Y., Zhu, X., Burrell, A.J., Mohanty, S.S., Atwood, J.A., Orlando, R., Scheller, H.V., and Mohnen, D. (2011). Galacturonosyltransferase (GAUT)1 and GAUT7 are the core of a plant cell wall pectin biosynthetic homogalacturonan:galacturonosyltransferase complex. Proc. Natl. Acad. Sci. USA 108: 20225-20230.

Babyatsky, M.W., and Podolsky, D.K. (1999). Growth and development of the gastrointestinal tract. Textbook of gastroenterology. In: Yamada,
T. (Ed.). Lippincott Williams \& Willkins, Philadelphia, pp 547-584.

Baker, S.J. (1973). Geographical variations in the morphology of the small intestinal mucosa in apparently healthy individuals. Pathol. Microbiol. 39: 222-237.

Bar-Peled, M., Urbanowicz, B.R., and O'Neill, M.A. (2012). The Synthesis and Origin of the Pectic Polysaccharide Rhamnogalacturonan II - Insights from Nucleotide Sugar Formation and Diversity. Front. Plant Sci. 3: 92

Bernfield, M., Götte, M., Park, P.W., Reizes, O., Fitzgerald, M.L., Lincecum, J., and Zako, M. (1999). Functions of cell surface heparan sulfate proteoglycans. Ann. Rev. Biochem. 68: 729-777.

Bishop, J.R., Schuksz, M., and Esko, J.D. (2007). Heparan sulphate proteoglycans fine-tune mammalian physiology. Nature 446: 1030-1037.

Braconnot, H. (1825). Investigations into a new acid spread throughout all plants. Ann. Chim. Phys. 2: 173-178.

Brown, L., Rosner, B., Willett, W.W., and Sacks, F.M. (1999). Cholesterollowering effects of dietary fiber: A meta-analysis. Amer. J. Clin. Nutr. 69: 30-42.

Brown, R.C., Kelleher, J., and Losowsky, M.S. (1979). The effect of pectin on the structure and function of the rat small intestine. Br. J. Nutr. 42: 357-365.

Burkitt, D.P. (1971). Epidemiology of cancer of the colon and rectum. Cancer 28: 3-13.

Cassidy, M.M., Lightfoot, F.G., and Vahouny, G.V. (1982). Morphological aspects of dietary fibers in the intestine. Adv. Lipid Res. 19: 203-229.

Chun, W., Bamba, T., and Hosoda, S. (1989). Effect of pectin, a soluble dietary fiber, on functional and morphological parameters of the small intestine in rats. Digestion 42: 22-29.

Crosnier, C., Stamataki, D., and Lewis, J. (2006). Organizing cell renewal in the intestine: Stem cells, signals and combinatorial control. Nature Rev. Genet. 7: 349-359.

Ehrlich, F. (1917). Pectinstoffe, ihre Konstitution und Bedeutung. Chem. Ztg. 41: 197-208.

Frese, M.A., Milz, F., Dick, M., Lamanna, W.C., and Dierks, T. (2009). Characterization of the human sulfatase Sulf1 and its high affinity heparin/heparan sulfate interaction domain. J. Biol. Chem. 284: $28033-$ 28044.

Gilcrease, M.Z. (2007). Integrin signaling in epithelial cells. Cancer Letters 247: $1-25$.

Habuchi, O. (2000). Diversity and functions of glycosaminoglycan sulfotransferases. Biochim. Biophys. Acta - General Subj. 1474: 115-127.

Held, M.A., Be, E., Zemelis, S., Withers, S., Wilkerson, C., and Brandizzi, F. (2011). CGR3: A golgi-localized protein influencing homogalacturonan methylesterification. Molec. Plant 4: 832-844.

Henglein, F.A., and Schneider, G. (1936). Über die Veresterung von Pektinstoffen. Ber. d. Chem. Ges. B 69: 309-324.

Hipsley, E.H. (1953). Dietary "fibre" and pregnancy toxaemia. Bri. Med. J. 2: 420-422.

lozzo, R.V., and Schaefer, L. (2015). Proteoglycan form and function: A comprehensive nomenclature of proteoglycans. Matrix Biol. 42: 11-55.

Kertesz, Z.I., Baker, G.L., Joseph, G.H., Mottern, H.H., and Olsen, A.G. (1944). Report of the committee for the revision of nomenclature of pectic substances. Chem. Eng. News 22: 105-106.

Kuwada, S.K., Kuang, J., and Li, X. (2005). Integrin $\alpha 5 / \beta 1$ expression mediates HER-2 down-regulation in colon cancer cells. J. Biol. Chem. 280: 19027-19035.

Kuwada, S.K., and Li, X. (2000). Integrin alpha5/beta1 mediates fibronectin-dependent epithelial cell proliferation through epidermal growth factor receptor activation. Mol. Biol. Cell 11: 2485-2496.

Lamanna, W.C., Frese, M.A., Balleininger, M., and Dierks, T. (2008). Sulf loss influences $\mathrm{N}-, 2-\mathrm{O}-$, and 6-O-sulfation of multiple heparan sulfate proteoglycans and modulates fibroblast growth factor signaling. J. Biol. Chem. 283: 27724-27735.

Langhout, D.J., Schutte, J.B., Van Leeuwen, P., Wiebenga, J., and Tamminga, S. (1999). Effect of dietary high- and low-methylated citrus pectin on the activity of the ileal microflora and morphology of the small intestinal wall of broiler chicks. Br. Poult. Sci. 40: 340-347.

Lee, J.C., Pak, S.C., Lee, S.H., Na, C.S., Lim, S.C., Song, C.H., Bai, Y.H., and Jang, C.H. (2004). Asian pear pectin administration during presensitization inhibits allergic response to ovalbumin in BALB/c mice. J. Altern. Complement Med. 10: 527-534. 
Li, J.P., and Kusche-Gullberg, M. (2016). Heparan Sulfate: Biosynthesis, Structure, and Function. International Review of Cell and Molecular Biology. Vol. 325, pp 215-273.

Maxwell, E.G., Belshaw, N.J., Waldron, K.W., and Morris, V.J. (2012). Pectin - An emerging new bioactive food polysaccharide. Trends Food Sci. Technol. 24: 64-73.

McCullough, J.S., Ratcliffe, B., Mandir, N., Carr, K.E., and Goodlad, R.A. (1998). Dietary fibre and intestinal microflora: Effects on intestinal morphometry and crypt branching. Gut 42: 799-806.

Mertens, G., Van Der Schueren, B., Van Den Berghe, H., and David, G. (1996). Heparan sulfate expression in polarized epithelial cells: The apical sorting of glypican (GPI-anchored proteoglycan) is inversely related to its heparan sulfate content. J. Cell Biol. 132: 487-497.

Mohnen, D. (2008). Pectin structure and biosynthesis. Curr. Opin. Plant Biol. 11: 266-277.

Nagel, M.D., Verhoef, R., Schols, H., Morra, M., Knox, J.P., Ceccone, G., Della Volpe, C., Vigneron, P., Bussy, C., Gallet, M., Velzenberger, E., Vayssade, M., Cascardo, G., Cassinelli, C., Haeger, A., Gilliland, D., Liakos, I., Rodriguez-Valverde, M., and Siboni, S. (2008). Enzymaticallytailored pectins differentially influence the morphology, adhesion, cell cycle progression and survival of fibroblasts. Biochim. Biophys. Acta - Gen. Subjects 1780: 995-1003.

Naqash, F., Masoodi, F.A., Rather, S.A., Wani, S.M., and Gani, A. (2017). Emerging concepts in the nutraceutical and functional properties of pectin-A Review. Carbohyd. Polym. 168: 227-239.

Nishida, M., Murata, K., Kanamaru, Y., and Yabe, T. (2014). Pectin of Prunus domestica L. alters sulfated structure of cell-surface heparan sulfate in differentiated Caco- 2 cells through stimulation of heparan sulfate 6-O-endosulfatase-2. Biosci., Biotechnol. Biochem. 78: 635-643.

Nishida, M., Murata, K., Oshima, K., Itoh, C., Kitaguchi, K., Kanamaru, Y., and Yabe, T. (2015). Pectin from Prunus domestica L. induces proliferation of IEC- 6 cells through the alteration of cell-surface heparan sulfate on differentiated Caco-2 cells in co-culture. Glycoconjugate J. 32: 153-159.

Nogami, K., Suzuki, H., Habuchi, H., Ishiguro, N., Iwata, H., and Kimata, K. (2004). Distinctive Expression Patterns of Heparan Sulfate O-Sulfotransferases and Regional Differences in Heparan Sulfate Structure in Chick Limb Bluds. J. Biol. Chem. 279: 8219-8229.

O'Neill, M.A., Ishii, T., Albersheim, P., and Darvill, A.G. (2004). RHAMNOGALACTURONAN II: Structure and Function of a Borate Cross-Linked Cell Wall Pectic Polysaccharide. Ann. Rev. Plant Biol. 55: 109-139.

Ohkami, H., Tazawa, K., Yamashita, I., Shimizu, T., Murai, K., Kobashi, K., and Fujimaki, M. (1995). Effects of Apple Pectin on Fecal Bacterial Enzymes in Azoxymethane-induced Rat Colon Carcinogenesis. Jap. J. Cancer Res. 86: 523-529.

Olano-Martin, E., Gibson, G.R., and Rastall, R.A. (2002). Comparison of the in vitro bifidogenic properties of pectins and pectic-oligosaccharides. J. Appl. Microbiol. 93: 505-511.

Popov, S.V., Ovodova, R.G., Popova, G.Y., Nikitina, I.R., and Ovodov, Y.S. (2005). Adhesion of human neutrophils to fibronectin is inhibited by co- maruman, pectin of marsh cinquefoil Comarum palustre L., and by its fragments. Biochemistry (Mosc) 70: 108-112.

Sarrazin, S., Lamanna, W.C., and Esko, J.D. (2011). Heparan Sulfate Proteoglycans. Cold Spring Harbor Perspect. Biol. 3: 1-33.

Sato, T., Van Es, J.H., Snippert, H.J., Stange, D.E., Vries, R.G., Van Den Born, M., Barker, N., Shroyer, N.F., Van De Wetering, M., and Clevers, H. (2011). Paneth cells constitute the niche for Lgr5 stem cells in intesti- nal crypts. Nature 469: 415-418.

Schlaepfer, D.D., and Hunter, T. (1997). Focal adhesion kinase overexpression enhances Ras-dependent integrin signaling to ERK2/mitogenactivated protein kinase through interactions with and activation of c-Src. J. Biol. Chem. 272: 13189-13195.

Schlaepfer, D.D., Jones, K.C., and Hunter, T. (1998). Multiple Grb2-mediated integrin-stimulated signaling pathways to ERK2/mitogen-activated protein kinase: summation of both c-Src- and focal adhesion kinase-initiated tyrosine phosphorylation events. Mol. Cell. Biol. 18: 2571-2585.

Schols, H.A., and Voragen, A.G. (2003). Pectic Polysaccharides. Handbook of Food Enzymology. In: Whitaker, J.R., Voragen, A.G.J., and Wong, D.W.S. (Ed.). Marcel Dekker, New York, NY.

Silva, J.A., and Rao, M.A. (2006). Pectins: Structure, Functionality, and Uses. Food Polysaccharides and Their Applications. In: Stephen, A.M., Phillips, G.O., and Williams, P.A. (Ed.). CRC Press, Boco Raton, FL, pp 353-411.

Simon-Assmann, P. (1989). Origin and deposition of basement membrane heparan sulfate proteoglycan in the developing intestine. J. Cell Biol. 109: 1837-1848.

Srivastava, P., and Malviya, R. (2011). Sources of pectin, extraction and its applications in pharmaceutical industry - an overview. Indian J. Nat. Prod. Resour. 2: 10-18.

Tasman-Jones, C., Owen, R.L., and Jones, A.L. (1982). Semipurified dietary fiber and small-bowel morphology in rats. Dig. Dis. Sci. 27: 519-524.

Tazawa, K., Yatuzuka, K., Yatuzuka, M., Koike, J., Ohkami, H., Saito, T., Ohnishi, Y., and Saito, M. (1999). Dietary fiber inhibits the incidence of hepatic metastasis with the anti-oxidant activity and portal scavenging functions. Hum Cell 12: 189-196.

Terpstra, A.H.M., Lapre, J.A., de Vries, H.T., and Beynen, A.C. (1998). Dietary pectin with high viscosity lowers plasma and liver cholesterol concentration and plasma cholesteryl ester transfer protein activity in hamsters. J. Nutr. 128: 1944-1949.

Trowell, H. (1972). Crude fibre, dietary fibre and atherosclerosis. Atherosclerosis 16: 138-140.

Vauguelin, M. (1790). Analyse du tamarin. Ann. Chim. (Paris) 5: 92.

Verderio, E., Nicholas, B., Gross, S., and Griffin, M. (1998). Regulated expression of tissue transglutaminase in Swiss 3 T3 fibroblasts: Effects on the processing of fibronectin, cell attachment, and cell death. Exp. Cell Res. 239: 119-138.

Voragen, A.G.J., Coenen, G.J., Verhoef, R.P., and Schols, H.A. (2009). Pectin, a versatile polysaccharide present in plant cell walls. Struct. Chem. 20: 263-275.

Wary, K.K., Mainiero, F., Isakoff, S.J., Marcantonio, E.E., and Giancotti, F.G. (1996). The adaptor protein Shc couples a class of integrins to the control of cell cycle progression. Cell 87: 733-743.

Wary, K.K., Mariotti, A., Zurzolo, C., and Giancotti, F.G. (1998). A requirement for caveolin-1 and associated kinase Fyn in integrin signaling and anchorage-dependent cell growth. Cell 94: 625-634.

Willert, K., Brown, J.D., Danenberg, E., Duncan, A.W., Weissman, I.L., Reya T., Yates, J.R., and Nusse, R. (2003). Wnt proteins are lipid-modified and can act as stem cell growth factors. Nature 423: 448-452.

Yamamoto, S., Nakase, H., Matsuura, M., Honzawa, Y., Matsumura, K., Uza, N., Yamaguchi, Y., Mizoguchi, E., and Chiba, T. (2013). Heparan sulfate on intestinal epithelial cells plays a critical role in intestinal crypt homeostasis via Wnt/ $\beta$-catenin signaling. Amer. J. Physiol. Gastrointest. Liver Physiol. 305: G241-G249. 